\title{
LETTERS
}

\section{Smoking is the first cause of morbidity and death in psychiatric settings}

Gatov and colleagues' concern for the dramatic premature death of patients with schizophrenia " 8 years younger than those without schizophrenia" was a missed opportunity to call a spade a spade. ${ }^{1}$

The issue is not new: adults with schizophrenia are 3.5 times more likely to die than the general population, mainly because of lung cancer, and chronic obstructive pulmonary and cardiovascular diseases; standardized mortality ratios are $52 / 100000$ person-years for suicide versus 75 for lung cancer in this group. ${ }^{2}$

Knudsen's enduring crusade against smoking showed sad evidence that the problem remains unchanged. ${ }^{3}$

Why are specific benefits of smoking cessation in the psychiatric setting almost ignored? In a randomized controlled trial, nicotine replacement therapy prevented agitation and neuroleptics use in smokers with schizophrenia admitted to the emergency department. ${ }^{4}$ Whatever immediate effects smoking may have on perceived stress (decreasing pain caused by withdrawal syndrome), overall smoking generates or aggravates negative emotional states. ${ }^{5}$ A time-series analysis showed that smoke-free policy reduced the incidence of physical assaults in psychiatric settings. ${ }^{6}$ Robust evidence has been available since 2004 showing that tobacco cessation treatment improves other outcomes for substance use (alcohol and illicit drugs) and predicts more favourable long-term outcomes. ${ }^{3}$ Last, treatments are safe and effective. ${ }^{7}$
However, it is most depressing that a recent article called for "resources" in implementing smoke-free policies and concluded that "research into the effect of smoking cessation on mental illnesses should also be a priority."

\section{Alain Braillon MD PhD}

Senior consultant, Centre Hospitalier Universitaire d'Amiens, Amiens, France

- Cite as: CMAJ 2017 December 11;189: E1534. doi: 10.1503/cmaj.733483

\section{References}

1. Gatov E, Rosella L, Chiu M, et al. Trends in standardized mortality among individuals with schizophrenia, 1993-2012: a population- based, repeated cross-sectional study. CMAJ 2017;189:E1177-87.

2. Olfson M, Gerhard T, Huang C, et al. Premature mortality among adults with schizophrenia in the United States. JAMA Psychiatry 2015;72:1172-81.

3. Knudsen HK. Implementation of smoking cessation treatment in substance use disorder treatment settings: a review. Am J Drug Alcohol Abuse 2017;43:215-25.

4. Allen MH, Debanné M, Lazignac C, et al. Effect of nicotine replacement therapy on agitation in smokers with schizophrenia: a double-blind, randomized, placebo-controlled study. Am J Psychiatry 2011;168:395-9.

5. Hajek P, Taylor T, McRobbie H. The effect of stopping smoking on perceived stress levels. Addiction 2010;105:1466-71.

6. Robson D, Spaducci G, McNeill A, et al. Effect of implementation of a smoke-free policy on physical violence in a psychiatric inpatient setting: an interrupted time series analysis. Lancet Psychiatry 2017;4:540-6.

7. Anthenelli RM, Benowitz NL, West R, et al. Neuropsychiatric safety and efficacy of varenicline, bupropion, and nicotine patch in smokers with and without psychiatric disorders (EAGLES): a double-blind, randomised, placebo-controlled clinical trial. Lancet 2016;387:2507-20.

8. Gage SH, Maynard OM. Smoke-free policies in psychiatric hospitals need resources. Lancet Psychiatry 2017;4:509-10.

Competing interests: None declared. 